\title{
Determination of quality in stored pear fruits by chemical analysis and sensorial judgement
}

\author{
Takácsné Hájos, $M^{1}$., Nyéki, $\mathbf{J}^{1}$., Illés, $A^{1}$., Sipos, Gy² \& Szabó, $Z^{1}$. \\ ${ }^{1}$ University of Debrecen, Centre of Agricultural Sciences and Engineering, Faculty of Agricultural \\ and Food Sciences and Environmental Management, H-4032 Debrecen, Böszörményi str. 138. \\ ${ }^{2}$ Gyümölcskert Sharing Company, H-8800 Nagykanizsa, Csengery str. 90.
}

\begin{abstract}
Summary: Aim of this research/project to determine the external and internal preferences of pear using descriptive sensory analysis, consumer preference. The research was performed on local consumers. Destructive measurements included firmness by puncture tests, soluble solids content (SSC), titrated acidity (TA). While there is a general positive trend for increasing preference with firmness, some consumers will prefer softer apples, and some will dislike the firmest pear.

Sensorial judgement is able to classify the attractiveness, preference of properties specific for pear. Tests were performed by 13 persons on 4 pear varieties (Bosc kobak, Conference, Packham's Triumph, Dessertnaia) checking 11 sensorial properties on a scale of 1 to 100 points. Relations of measurements and judgements were processed by correlation analysis. For analysis, the objects were furnished in 2011 from different growing sites (Csenger, Mérk and Nagykanizsa), taking from the store (in January) immediately. Among those the best notes were given to Bosc kobak and Conference coming from Mérk and to Packham's Triumph grown at Nagykanizsa.

It was stated that the success of sensorial judgement depends on the state of maturity, which is difficult to guarantee to be synchronous among samples of different varieties. Mature fruits are more praised as a sample of Bosc kobak taken from a chain of department store proved to be of balanced composition regarding its sugar/acid ratio $(0.12)$ and the optimal firmness $\left(5.75 \mathrm{~N} / \mathrm{cm}^{2}\right)$.

Results of the correlation analysis suggest that the thickness of the skin is a decisive component of preference ( $\mathrm{r}=0.857)$, the typical pearflavour $(r=0.948)$, the taste as sweetness and acidity $(r=0.930$ and $r=0.813)$. At the same time, no valuable relation could be detected between the data raised in the laboratory and the preference expressed by the sensorial tests, which should signalise that the opinion of consumers does not depend on any individual parameter obtained in the laboratory (sugar- or acid content, firmness) but rather on the complexity of several decisive components together (sweetness, acidity, flavour, skin, etc.).

The consumers' preference cannot be measured objectively without the aid of adequate expertise and a prosperous surrounding, samples of optimal maturity and a thoughtfully edited judging form
\end{abstract}

Key words: pear varieties, sensorial judgement, parameters of quality, water soluble solids (Brix\%), acidity (\%), flesh firmness, correlation

\section{Introduction}

Pear (Pyrus communis L.) belongs to the family Rosaceae and subfamily Pomoideae. It is one of the most important tree fruit of the world. Out of the several species the pear is most widely grown. The pear is considered by many to be among the most delicious of all species. It contains a better juicy texture with a delicate flavour and aroma (Iftikhar et al., 2009). The common Hungarian varieties of pear are Bosc kobak, Conference, Packham's Triumph and Williams pear. Except the William pear the other pears are winter varieties and can be stored for longer period.

Eating quality is difficult to measure objectively. Analytical measurements of soluble solids (\% SS), titratable acidity (TA) and firmness have shown poor correlation with sensory perceptions of sweetness, sourness and texture (Bourne, 1979, Watada et al., 1981).

Fruit quality includes many properties such as sensory attributes (appearance, texture and flavour), nutritional value, chemical constituents, mechanical properties, functional properties and defects (Abbott, 1999).

The quality attributes can be described by colour, texture flavour, and taste (sweet, sour, salt and bitter sensations) in addition to physical attributes such as size and shape. All these attributes can be evaluated by using trained sensory panel, but more rapid and objective characterisation is achieved by instrumental measurements. Texture and flavour appear to be the most important attributes for the consumer (Stow, 1995)

Appearance of fruit in the marketplace is a critical importance to consumer, often setting up expectation of what the product will taste like (Deliza \& MacFie, 1996; Jaeger \& MacFie, 2011). External factors of the appearance of fruit, such as shape and colour, can have a large influence on the consumer's first impression and opinion of what the fruit may taste like (Jaeger \& MacFie, 2001). Colour is probably the most important appearance characteristic of foods, especially if some other aspect of quality is related to the colour. It seems likely that recognition of cultivar as well as 
the general appearance and condition of produce is important to pear purchasers.

Flavour is specifically important that fresh fruits have an excellent external appearance in addition to good flavour and texture (Suwanagul \& Richardson, 1998). The flavour of a food product includes the olfactory sensations caused by volatile substances released from the product (aroma), gustatory sensations (taste) and trigeminal sensations such as astringency (Meilgaard et al., 1987). It is, however, well known that the colour and texture of food products can also influence the overall judgment of a particular flavour (Redgwell \& Fischer, 2002). Aroma is one of the most important sensory attributes of fruit (Zhang et al., 2008). It has been found that there are close correlations between pear aroma and flavour which indicates the importance of volatile aromatics to flavour as they make a pear taste like a pear (Eccher Zerbini, 2002; Quamme \& Marriage, 1977).

Texture was defined by Szczesniak (1990) as "the sensory manifestation of the structure of the food and the manner in which this structure reacts to the applied forces, the specific senses being involved being vision, kinaesthesia, and hearing". It is an important quality attribute of fresh fruit and vegetables, however, flavour often overshadows the texture of a product (Nicolai et al., 2003). Ripening is the key factor for fruit texture and thus ultimately fruit quality.

Sensory analysis plays a large role in supporting breeding and introduction of new cultivars into the marketplace (Hampson et al., 2000). Sensory analysis has been defined as "a scientific discipline used to evoke, measure, analyse, and interpret reactions to those characteristics of foods and materials as they are perceived by the senses of sight, smell, taste, touch, and hearing" (IFT, 1975).

For quality evaluation of pears sensory, chemical and physical measurements are often determined. Instrumental texture measurements, as well as sugar and acid contents are rapid measurements used to determine quality of apples after harvest and to follow changes during storage.

One of the challenges in sensory evaluation of fruit is product variability. Differences in soil, climate and cultural management produce site-to-site variation, while individual fruit off the same tree may vary in characteristics such as firmness, \% SS, acidity and colour. This variation is not always evident externally and so cannot be controlled by visual classification. In addition, perceptible differences in sweetness, crispness and fruit flavour exist within fruits from top to bottom and side to side (Dever et al., 1995)

\section{Material and method}

Five fresh, mature and healthy commercially grown pear cultivar was harvested in Csenger, Merk and Nagykanizsa in August 2011. For the excellent maturity, taste, flavour, smell, crispiness pears have been stored at $+0,50 \mathrm{C}$ at GYKSZNK $\mathrm{Kft}$. in Ujfeherto. The recommended interval of temperature in the store is $+0,5$ and $-0,10 \mathrm{C}$. Higher temperatures reduce the possible storing period substantially (Soltesz, 1997). Two of the 13 samples were purchased from Tesco and Cora hypermarkets

Table 1. Comparison of the results of sensorial tests and measurements obtains in the laboratory regarding the quality of pear varieties. Debrecen, 2012

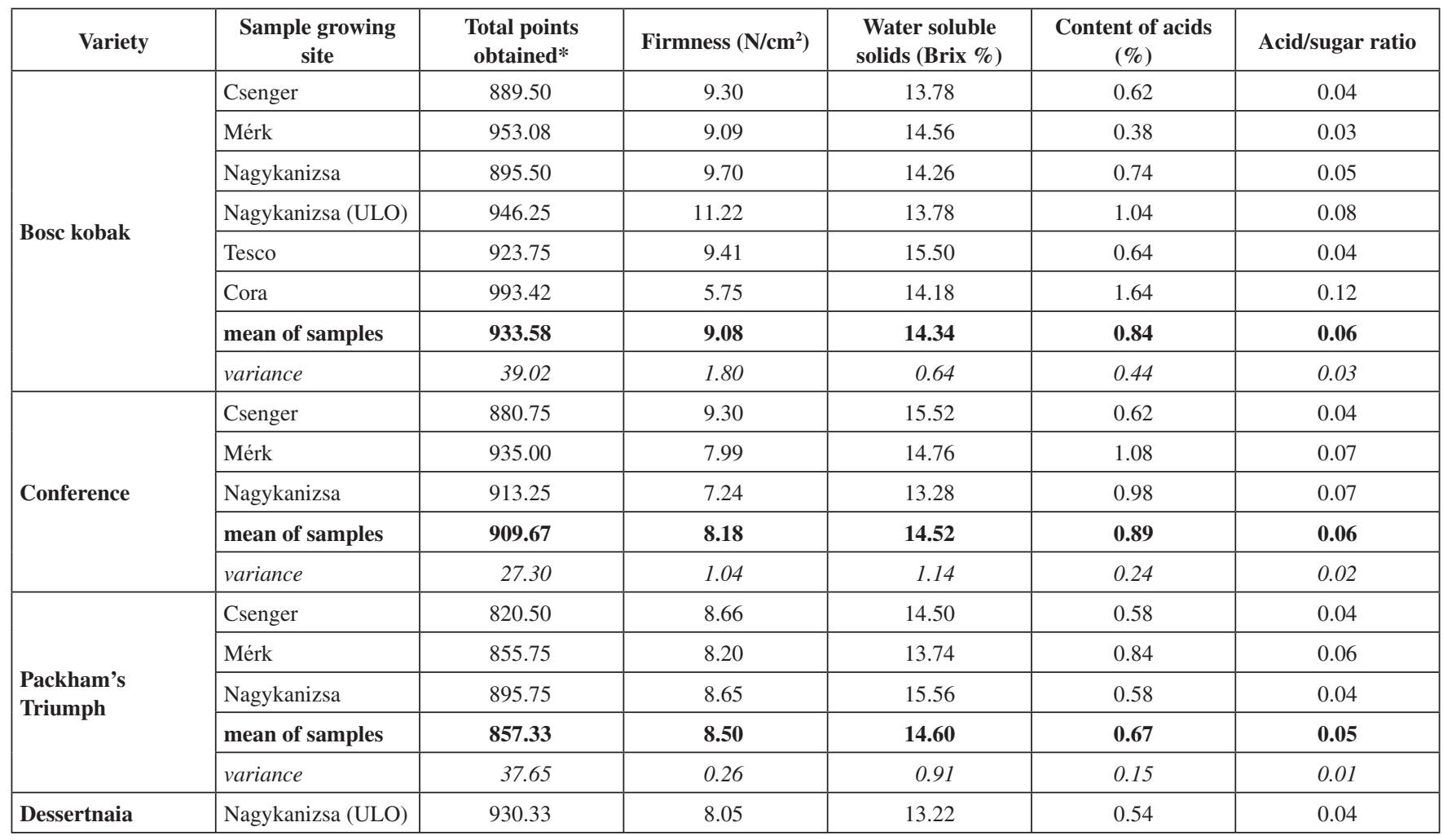

*points obtained for 11 properties (maximum: 1100 points) 
in Debrecen. Before the sensory analysis started the internal preferences (total soluble solids, acid and flesh firmness) of the pears have measured. After washing, sorting and coring the fruit pieces were made with the help of stainless steel knife and placed on a plate. On another plate the whole fruits were put.

For the performance of the session we applied the principles and methods earlier developed (Takácsné Hájos et al., 2010). Samples coming from different sites have been coded. On the form 11 questions have to be answered and each will be rated on a scale of 1-100.

Results are visualised by diagrams, and the relations revealed as correlations.

\section{Results and discussion}

Results of measurements and tests performed in the laboratory and the ratings of the sensorial sessions are presented in Table 1 and Figure 1. The maximum of points is 1100. Best rate received the variety Bosc kobak (933.58 points as mean of all tests), on the best growing site, Mérk (953.08), almost the same value at Nagykanizsai in ULO store (946.25).

The value of the samples depends largely on the maturity of fruits taken from the department stores. Those Bosc samples furnished by the store of Cora were optimally ripe, i.e. ready for consumption. The adequate sign of maturity is the firmness, which showed about half of the values of other samples (5.75 $\mathrm{N} / \mathrm{cm}^{2}$ ). On the contrary, water soluble solids were as high as the mean of varieties $(14.18 \%)$, whereas acidity (1.64\%) was two times higher. That sample gave the highest sugar/acid ratio (0.12), which was prosperous from the point view of sensorial rating and thus achieved the highest record (993.42).

Samples of Conference excelled also when coming from Mérk (total being 935 points), which means good sugar (14.75 $\%$ ) and acids (1.08\%), which also being in optimal for taste.

Among samples coming from the same growing sites, Packham's Triumph proved to be the next best variety, but samples of Nagykanizsa received the highest number of points: 895.75 . Firmness of samples was nearly equal in the three samples $\left(8.20-8.66 \mathrm{~N} / \mathrm{cm}^{2}\right)$, but the water soluble solids was higher at Nagykanizsa $(15.56 \%)$ combined with a lower acid content $(0.58 \%)$.

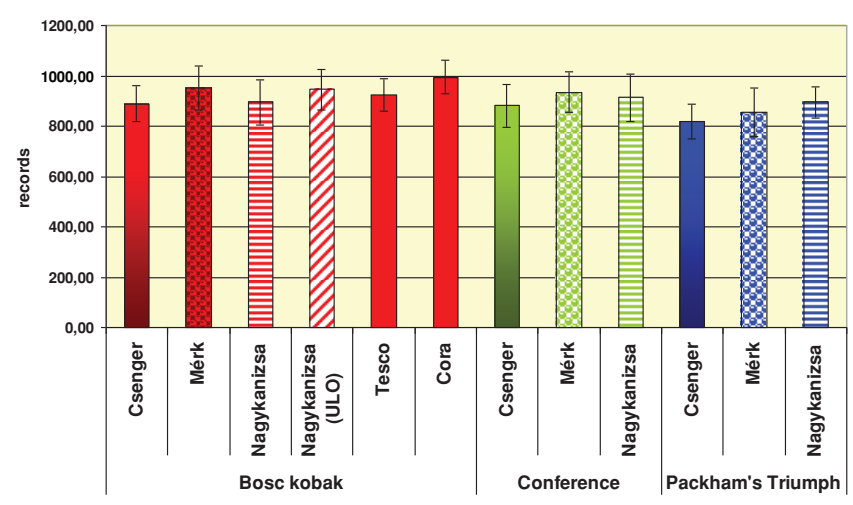

Figure 1. Records of sensorial ratings of fruits coming from different sources of three varieties
A peculiar, less known variety, Dessertnaia, excelled with its pleasant individual flavour and received high rates (930.33 points), with lower sugar content (13.22\%) and acids $(0.54 \%)$.

As visible in the results, that not so much the absolute value of parameters alone were appreciated by the panel, but rather the relations or harmony between the properties (e.g. sugar/acid ratio), which could be expressed by the word: taste.

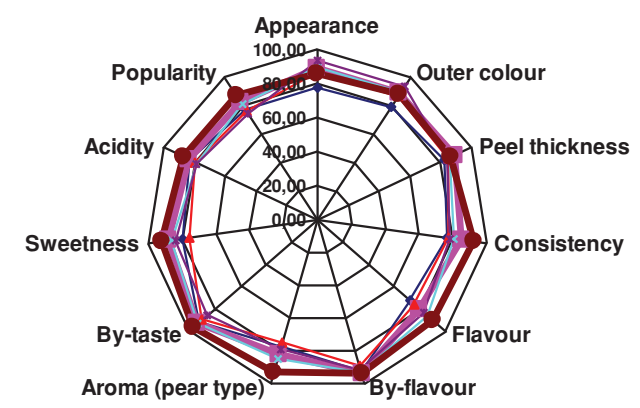

\begin{tabular}{ll|}
$\rightarrow \rightarrow$ Bosc kobak Csenger & Bosc kobak Mérk \\
$\rightarrow-$ Bosc kobak Nagykanizsa & - Bosc kobak Nagykanizsa (ULO) \\
$\rightarrow$-Bosc kobak Tesco & Bosc kobak Cora \\
\hline
\end{tabular}

Figure 2. Bosk kobak

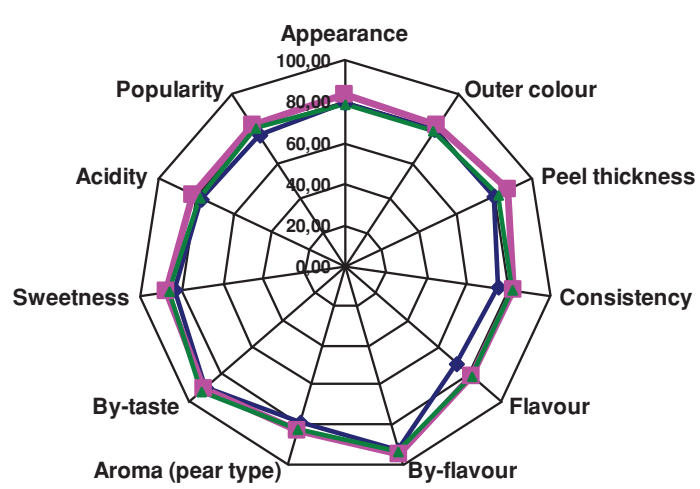

$\sim$ Conference Csenger $\triangle$ Conference Mérk $\rightarrow$ Conference Nagykanizsa

Figure 3. Conference

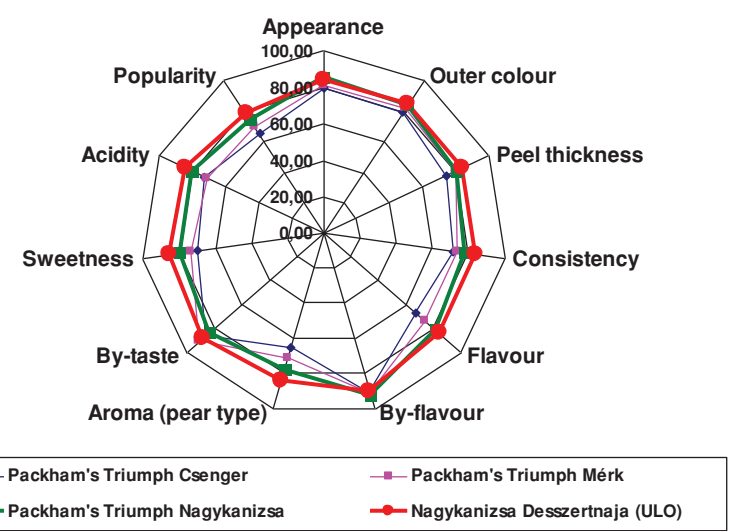

Figure 4. Packham's Triumph and Dessertnaia 
Diagrams of Figure 1 show the points given to fruits of three pear varieties grown at different sites after sensorial rating. The best score was given to Bosc kobak coming from the chain store Cora, while the other two varieties proved to be slightly inferior: Conference and Packham's Triumph.

The ratings of the sensorial tests was depicted by radial diagrams (Figure 2-4), where all the 13 persons' expressed their opinion. The saturation of the shape means the uniformity of the properties observed. It's best recognised in Bosc kobak (Figure 2), where all values of the score were high in the diagram. Among the most mature samples, it was unique in earning near maximum score in flavour.

Thus, it is convincing that full maturity is the most adequate period, when decisions are most valid, i.e. ready for immediate consumption. In the future, we must agree that the most important components of the quality do not attain their maxima at the same time. If fragrance and flavour are considered, taste, sweetness and acidity cannot be optimal in spite if genetically well founded. The variety Conference was represented by three growing sites, where the commune Mérk proved to be the best, although the typical pear flavour was not appreciated (Figure 3).

\section{Acknowledgement}

Research was sponsored by NFÜ TECH-08-A3/2-20080373grant.

In Figure 4, three samples of Packham's Triumph were combined with the data of Dessertnaia, which was stored in the same ULO (ultra low oxygen) store at Nagykanizsa, and was appreciated for its special flavour and smell.
The correlations between the scores of the sensorial tests and the data obtained in the laboratory are presented in the matrix of Table 2.

It could be stated that the popularity of fruits is largely determined by the thickness of the fruit peel $(\mathrm{r}=0.857)$, flavour $(r=0.800)$, and by the aroma $(r=0.948)$, sweetness $(\mathrm{r}=0.930)$ and freshness due to the acidity $(\mathrm{r}=0.813)$.

Those relationships prove the decisive components: flavour, taste and aroma being considered first of all. It is important that the samples must represent identical state of maturity. The relation between taste: acidity and sweetness $(r=0.749)$ tells us the important harmony being equally contributed by both components. Similarly, the firmness and flavour are closely related with sweetness and special pear flavour.

As no one parameter of measurements obtained in the laboratory showed close relation with sensorial scores. It tells us that the content of acids or sugar alone does not decide the value of the fruit from the point of view of the consumer. Those components together are responsible for the harmony of taste and for freshness.

\section{References}

Abbott, J. A. (1999): Quality measurement of fruits and vegetables. Postharvest Biology and Technology. 15; 207-225.

Bourne, M.C. (1979): Rupture test vs. small-strain test in predicting consumer response to texture. Food Technology 10: 67-70.

Deliza, R. \& MacFie, H.J.H. (1996): The generation of sensory expectation by external cues and its effect on sensory perception and hedonic ratings: a review. J. Sensory Stud. 11 (2): 103-128.

Dever, M.C., Cliff, M.A. \& Hall, J.W. (1995): Analysis of variation and multivariate relationships among analytical and sensory

Table 2. Matrix of correlations between sensorial scores and data obtained by laboratory tests on pear fruits $(\mathrm{n}=13)$

\begin{tabular}{|c|c|c|c|c|c|c|c|c|c|c|c|c|c|}
\hline & 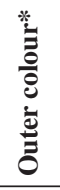 & 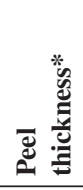 & 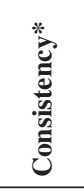 & 䓂 & 泀 & 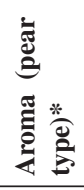 & 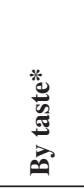 & 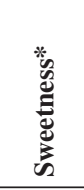 & $\stackrel{*}{*}$ & 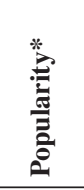 & 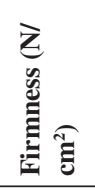 & 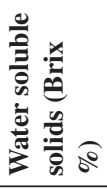 & 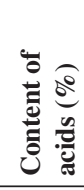 \\
\hline Outer colour * & & 0.603 & 0.443 & 0.593 & -0.026 & 0.409 & 0.043 & 0.403 & 0.311 & 0.339 & 0.247 & 0.192 & 0.109 \\
\hline Peel thickness * & & & 0.769 & 0.721 & 0.395 & 0.767 & 0.556 & 0.791 & 0.715 & 0.857 & -0.008 & -0.115 & 0.304 \\
\hline Consistency * & & & & 0.872 & 0.577 & 0.914 & 0.590 & 0.876 & 0.823 & 0.590 & -0.516 & -0.212 & 0.570 \\
\hline Flavour * & & & & & 0.455 & 0.891 & 0.356 & 0.843 & 0.638 & 0.800 & -0.314 & -0.147 & 0.564 \\
\hline By flavour * & & & & & & 0.581 & 0.443 & 0.681 & 0.389 & 0.628 & -0.413 & 0.194 & 0.453 \\
\hline Aroma (pear type) * & & & & & & & 0.592 & 0.960 & 0.781 & 0.948 & -0.349 & -0.144 & 0.592 \\
\hline By taste * & & & & & & & & 0.543 & 0.410 & 0.720 & -0.283 & -0.543 & 0.620 \\
\hline Sweetness * & & & & & & & & & 0.749 & 0.930 & -0.272 & -0.050 & 0.452 \\
\hline Acidity * & & & & & & & & & & 0.813 & -0.301 & -0.097 & 0.239 \\
\hline Popularity * & & & & & & & & & & & -0.297 & -0.196 & 0.571 \\
\hline Firmness $\left(\mathrm{N} / \mathrm{cm}^{2}\right)$ & & & & & & & & & & & & 0.194 & -0.523 \\
\hline \multicolumn{14}{|c|}{ Water soluble solids (Brix \%) } \\
\hline Content of acids (\%) & & & & & & & & & & & & & \\
\hline
\end{tabular}

* parameters received from the onganoleptic panel 
characteristics in whole apple evaluation. J. Sci. Food Agric. 69: 329-338.

Eccher Zerbini, P. (2002): The quality of pear fruit. Acta Horticulturae, 600: 805-810.

Hampson, C. R., Quamme, H. A., Hall, J. W., MacDonald, R. A., King, M. C. \& Cliff, M. A. (2000): Sensory evaluation as a selection tool in apple breeding. Euphytica, 111: 79-90.

IFT. (1975): Minutes of sensory evaluation div. business meeting at 35th Ann. Meet., Inst. of Food Technologists, Chicago, June 10.

Iftikhar, S., Imtiaz, H., Alam, Z. \& Yasser, D., (2009): Sensory Evaluation and Microbial Analysis of Apple and Pear Mixed Fruit Jam Prepared from Varieties Grown in Azad Jammu and Kashmir, World Journal of Dairy \& Food Sciences 4 (2): 201-204.

Jaeger, S. R. \& MacFie, H. J. H. (2001): The effect of advertising format and means-end information on consumer expectations for apples. Food Quality and Preference, 12: 189-205.

Meilgaard, M., Civille, G. V. \& Carr, B. T. (1987): Sensory evaluation techniques. CRC Press, Boca Raton, Florida. 448. p.

Nicolai, B. M., Verlinden, B. E., De Baerdemaeker, J. \& Lammertyn, J. (2003): Texture assessment of perishable products. Acta Horticulturae, 600: 513-519.

Redgwell, R. J. \& Fischer, M. (2002): Fruit texture, cell wall metabolism and consumer perceptions. In: Fruit Quality and Its
Biological Basis (edited by M. Knee). pp. 46-75. Boca Raton: CRC Press.

Quamme, H. A. \& Marriage, P. B. (1977): Relationships of aroma compounds to canned fruit flavour among several pear cultivars. Acta Horticulturae, 69: 301-305.

Soltész M. (1997): Integrált gyümölcstermesztés. Mezőgazda Kiadó, Budapest, 843. p.

Stow, J. (1995): Quality measurements of apples. Postharvest News and Information, 6 (3): 32-33.

Suwanagul, A. \& Richardson, D. G. (1998): Identification of headspace volatile compounds from different pear (Pyrus communis L.) varieties. Acta Horticulturae, 475: 605-623.

Szczesniak, A. S. (1990): Phsychoreology and texture as factors controlling the consumer acceptance of food. Cereals Foods World, 351: 1201-1205.

Takácsné Hájos, M., Nyéki, J. \& Szabó ,Z. (2010): Organoleptic evaluation of pear varieties grown at different sites. International Journal of Horticultural Science. 26. (3): 33-39.

Watada, A.E., Abbott, J.A., Hardenburg, R.E. \& Lusby, W. (1981): Relationship of apple sensory attributes to headspace volatiles, soluble solids and titratable acids. J. Amer. Soc. Hort. Sci. 106: 130-132.

Zhang, H., Wang, J. \& Ye, S. (2008): Prediction of soluble solids content, firmness and $\mathrm{pH}$ of pear by signals of electronic nose sensors. Analytica Chimica Acta, 606: 112-118. 